\title{
New basal synapsid supports Laurasian origin for therapsids
}

Jun Liu, Bruce Rubidge, and Jinling Li

Acta Palaeontologica Polonica 54 (3), 2009: 393-400 doi: http://dx.doi.org/10.4202/app.2008.0071

The distant evolutionary ancestry of mammals is documented by a rich therapsid fossil record. While sphenacodontid synapsids are considered the sister-group of therapsids, the place of origin of therapsids is an enigma, largely because of a long standing morphological and temporal gap (Olson's Gap) in their fossil record. We describe a new large predatory synapsid, Raranimus dashankouensis gen. et sp. nov., from the Middle Permian of Dashankou in China which has a unique combination of therapsid and sphenacodontid features. This specimen is of great significance as it is a basal therapsid which is the sister taxon to all other therapsids. The fact that it was found in association with Early Permian tetrapods (Anakamacops and Belebey) suggests that it is the oldest therapsid and provides the first evidence of therapsid-bearing rocks which cover Olson's Gap. It further supports that therapsids may have had a Laurasian rather than Gondwanan origin.

Key words: Therapsida, Dashankou, Permian, Laurasia, China.

Jun Liu [liujun@ivpp.ac.cn] and Jinling Li [li.jinling@ivpp.ac.cn], Key Laboratory of Evolutionary Systematics of Vertebrates, Institute of Vertebrate Paleontology and Paleoanthropology, Chinese Academy of Sciences, Beijing 100044, China Bruce Rubidge [bruce.rubidge@wits.ac.za], Bernard Price Institute for Palaeontological Research, University of the Witwatersrand, Private Bag 3, WITS, Johannesburg, 2050, South Africa

This is an open-access article distributed under the terms of the Creative Commons Attribution License (for details please see creativecommons.org), which permits unrestricted use, distribution, and reproduction in any medium, provided the original author and source are credited. 
Full text $(403.0 \mathrm{kB})$ 
